\title{
Pro-oxidant and pro-apoptotic activity of polyphenol extract from Annurca apple and its underlying mechanisms in human breast cancer cells
}

\author{
STEFANIA D'ANGELO ${ }^{1,2 *}$, ELISA MARTINO ${ }^{2 *}$, CONCETTA PAOLA ILISSO $^{2}$, \\ MARIA LIBERA BAGAROLO ${ }^{2}$, MARINA PORCELLI ${ }^{2}$ and GIOVANNA CACCIAPUOTI ${ }^{2}$ \\ ${ }^{1}$ Department of Motor Sciences and Wellness, Parthenope University; ${ }^{2}$ Department of Biochemistry, \\ Biophysics, and General Pathology, University of Campania 'Luigi Vanvitelli', Naples, Italy
}

Received March 10, 2017; Accepted June 14, 2017

DOI: 10.3892/ijo.2017.4088

\begin{abstract}
Among nutraceuticals, polyphenols represent the most intriguing and studied class of compounds that can be therapeutics for a large spectrum of the most common diseases, including cancer. Although polyphenols are well known as potent antioxidants, a pro-oxidant effect has been associated with a pro-apoptotic function of these compounds in various types of tumor cells. Annurca apple, a southern Italian variety, is characterized by an extremely high content of polyphenols and displays a stronger antioxidant activity compared with other varieties. In the present study we explored the antiproliferative effect of Annurca apple polyphenol extract (APE) in human breast cancer MCF-7 cells and we investigated the underlying mechanisms. Results
\end{abstract}

Correspondence to: Professor Giovanna Cacciapuoti, Department of Biochemistry, Biophysics, and General Pathology, University of Campania 'Luigi Vanvitelli', Via L. De Crecchio 7, 80138 Naples, Italy

E-mail: giovanna.cacciapuoti@unicampania.it

${ }^{*}$ Contributed equally

Abbreviations: ROS, reactive oxygen species; APE, apple polyphenol extract; RPMI, Roswell Park Memorial Institute medium; ERK1/2, extracellular signal-regulated kinases $1 / 2$; pERK1/2, phospho-extracellular signal-regulated kinases $1 / 2$; MTT, 3-(4,5-dimethylthiazol-2-yl)-2,5-diphenyltetrazolium bromide; TBARS, thiobarbituric acid-reactive species; FACS, fluorescence-activated cell sorting; PARP, poly(ADP ribose) polymerase; PI, propidium iodide; PBS, phosphate-buffered saline; FBS, fetal bovine serum; HRP, horseradish peroxidase; HPLC, high performance liquid chromatography; TBS-T, Tris-buffered saline with Tween-20; SD, standard deviation; SDS-PAGE, sodium dodecyl sulfate-polyacrylamide gel electrophoresis; Annexin V-FITC, Annexin V-fluorescein isothiocyanate; $\mathrm{EqC}$, catechin equivalent

Key words: Annurca apple, polyphenol extract, lipid peroxidation, pro-oxidant, breast cancer, apoptosis, cell cycle, ERK1/2 signaling showed that at $500 \mu \mathrm{M}$ catechin equivalent (EqC) APE acts as a pro-oxidant increasing thiobarbituric acid-reactive species cell content of approximately 6 -fold more than the untreated cells. We found that APE strongly inhibits the proliferation of MCF-7 cells by inducing G2/M cell cycle arrest and apoptosis. Immunoblot analysis demonstrated that APE treatment increases the levels of p53 and p21, downregulates the expression of the cell cycle regulatory protein cyclin D1, and inhibits ERK1/2 phosphorylation. Moreover, APE treatment caused a marked increase of pro-apoptotic Bax/Bcl-2 ratio paralleled by caspase- $9,-6,-7$, and poly(ADP ribose) polymerase cleavage. Altogether our data indicate that APE, at elevated concentrations, acts as a potent pro-oxidant and antiproliferative agent able to downregulate ERK1/2 pathway leading to cell cycle inhibition and apoptosis and provides a rationale for its potential use in the development of novel therapeutics towards breast cancer.

\section{Introduction}

Considerable scientific interest in the anticancer therapy has been focused, for long time, on the identification of compounds able to efficiently commit cells to apoptosis. Apoptosis plays a crucial role in eliminating the mutated hyperproliferating cells from the system. Thus, induction of apoptosis in tumor cells may be considered as a protective mechanism against development and progression of cancer. Reactive oxygen species (ROS) play a major role in carcinogenesis (1). It has been shown that the formation of ROS contributes to the antitumor activity of several chemotherapeutic drugs. However, pro-oxidant molecules can act as selective cytotoxic agents against cancer cells by achieving toxic levels of ROS (1).

The validation and utilization of dietary components, natural products, or their synthetic analogs as chemopreventive agents in the form of foods or nutraceutical has become an important issue in health- and cancer-related research and a growing body of evidence also suggests that many natural compounds may cooperate in enhancing the therapeutic efficacy of chemotherapeutic drugs, help to by-pass cancer drug resistance or reduce side-effects of chemotherapy (2-4). Polyphenols represent one of the most interesting and investigated class of nutraceutical 
compounds because of their therapeutic properties for several common diseases, including cancer (5). It is reported that flavonoids, a class of polyphenolic compounds show several anticancer effects including apoptosis induction, cell cycle arrest, antiproliferative, antioxidative, antiangiogenic and antimetastatic action against many human cancer cell lines. Interestingly, an important aspect of the chemopreventive action of polyphenols is their differential activity in targeting cancer cells but not normal cells $(6,7)$. Most of the advantageous effects of natural polyphenols have been ascribed to their ability to scavenge free radicals endogenously generated or formed by radiation and xenobiotics. However, emerging evidence indicates that the anticancer and chemopreventive properties of plant-derived polyphenols are mainly related to their pro-oxidant activity (8). The main problem related to the use of polyphenols as anticancer agents is their poor bioavailability, which might hamper the in vivo effects of the single compound (9) and it has been suggested that combinations of polyphenols naturally found in fruits and vegetables could be most favorable for cancer prevention owing to synergic or additive biological effects (10).

Apples are widely consumed and represents one of the main sources of polyphenols in the Western diet (11). The antiproliferative properties of apple extracts have been described extensively by in vitro studies and products extracted from apple skins have been shown to be effective in preventing tumor formation in different types of cancer, including colorectal, breast, prostate, liver, cervical and lung (12-14).

Among the different varieties, great interest has been paid to Annurca apple, one of the most important cultivars of southern Italy with a 'Protected Geographical Indication' of the Campania region (15). The Annurca apple is characterized by an extremely high content of polyphenols, mainly catechin, epicatechin, and chlorogenic acid and displays a stronger antioxidant activity compared with other varieties (16). Many studies have recently investigated the polyphenol content of Annurca apple peel and have described its higher ability in comparison to other species in reducing cell cholesterol and glucose uptake (17) and its activity in chemoprevention of colorectal cancers $(18,19)$. Moreover, the antiproliferative effect of Annurca apple polyphenol extract has been described in human $\mathrm{HaCaT}$ keratinocytes where it induced p53-independent extrinsic apoptosis (20).

Breast cancer is the most common malignancy in women with increased incidence worldwide. Poor prognosis of breast cancer is partially attributed to multiple-drug resistance and anti-apoptosis activity of cancer cells (21). Although antitumor activity of polyphenols in breast cancer has been shown, its molecular mechanism is yet to be clarified (22).

In the present study, the pro-oxidant, antiproliferative, and pro-apoptotic effects of Annurca APE in human breast cancer MCF-7 cells were investigated and the potential underlying molecular mechanisms were explored. We found that Annurca APE is able to inhibit cell proliferation by inducing cell cycle arrest at G2/M and the activation of apoptosis via a Bcl2- Bax-dependent mitochondrial signaling pathway. Finally, we report that the antiproliferative effects of APE involve downregulation of cyclin D1, upregulation of p53 and p21, and inhibition of extracellular signal-regulated kinase 1/2 (ERK1/2) activation.

\section{Materials and methods}

Materials. Roswell Park Memorial Institute medium RPMI1640 medium (RPMI-1640), bovine serum albumin (BSA), 3-(4,5-dimethylthiazol-2-yl)-2,5-diphenyltetrazolium bromide (MTT), Folin-Ciocalteu reagent, propidium iodide (PI), thiobarbituric acid, and RIPA buffer were purchased from Sigma-Aldrich (St. Louis, MO, USA). Phosphate-buffered saline (PBS) and trypsin-EDTA were from Lonza (Milan, Italy). Fetal bovine serum (FBS) was purchased from Gibco (Grand Island, NY, USA). Tissue culture dishes were purchased from Microtech (Naples, Italy). Annexin V-fluorescein isothiocyanate (V-FITC) Apoptosis Detection kit was purchased from eBioscience (San Diego, CA, USA). Monoclonal antibodies to caspase-9, poly(ADP ribose) polymerase (PARP), Bax, Bcl-2, cyclin D1, p21, p53, $\beta$-actin, and polyclonal antibodies to caspases 6 and 7, ERK1/2, and pERK1/2 were purchased from Cell Signaling Technology (Beverly, MA, USA). Horseradish peroxidase (HRP)-conjugated goat anti-rabbit and HRP-conjugated goat anti-mouse secondary antibodies were obtained from ImmunoReagents, Inc., Raleigh, NC, USA. All buffers and solutions were prepared with ultra-high quality water. All reagents were of the purest commercial grade.

Apple samples. Annurca (Malus pumila Miller cv. Annurca) apple fruits (each weighing approximately $100 \mathrm{~g}$ ) were collected in Giugliano (Napoli, Italy) in October, when fruits had just been harvested (green peel). Fruits were reddened following the typical treatment for approximately 30 days and then analyzed (15).

Polyphenol extraction. APE extraction from Annurca apple was carried out as previously reported by D'Angelo et al (20). Briefly, 40 grams of Annurca apple flesh were homogenized for $5 \mathrm{~min}$ by a Tefal Rondo 500 homogenizer using $40 \mathrm{ml}$ of $80 \%$ methanol and $20 \%$ water plus $0.18 \mathrm{~N} \mathrm{HCl}$. After centrifugation $(18,000 \mathrm{x} \mathrm{g}$ for $25 \mathrm{~min})$, the slurry was dried under vacuum by using the Univapor Concentrator Centrifuge, model Univapo $100 \mathrm{H}$ (Uni Equip). The dried extracts were dissolved in $10 \mathrm{ml}$ of PBS and frozen at $-80^{\circ} \mathrm{C}$ until use.

Polyphenolic content and HPLC analysis. The total polyphenolic content of apple extract was assessed approximately by using the Folin-Ciocalteu phenol reagent as described by Singleton et al (23). The extracts $(100 \mu \mathrm{l})$ were mixed with the Folin-Ciocalteu phenol reagent $(0.5 \mathrm{ml})$, deionized water $(0.9 \mathrm{ml})$, and $\mathrm{Na}_{2} \mathrm{CO}_{3}(7.5 \% \mathrm{w} / \mathrm{v}, 4 \mathrm{ml})$. The absorbance at $765 \mathrm{~nm}$ was measured $1 \mathrm{~h}$ after incubation at room temperature using a Cary ultraviolet-visible spectrophotometer (Varian). Since APE is a mixture of different phenolic compounds, to give an arbitrary APE molar concentration the measurement was compared to a standard curve of prepared catechin solutions and expressed as milligrams of catechin equivalent (EqC) per $100 \mathrm{~g}$ of Annurca flesh fresh weight. The chemical characterization was performed in HPLC as reported by D'Angelo et al (24). All experiments were carried out in triplicate. HPLC separation of polyphenols was performed by reversed-phase chromatography on a $5 \mu \mathrm{m}$ column Kromasil $\mathrm{C}_{18}$ column $(150 \times 4.6 \mathrm{~mm})$, using a Beckman Apparatus (Gold-126) equipped with a UV detector fixed at 
$278 \mathrm{~nm}$. The column was eluted at a flow rate of $1.0 \mathrm{ml} / \mathrm{min}$ with $0.2 \%$ acetic acid, $\mathrm{pH} 3.1$ (A) and methanol (B) as the mobile phase; the gradient was changed as follows: $95 \% \mathrm{~A} / 5 \% \mathrm{~B}$ for $1 \mathrm{~min}, 85 \% \mathrm{~A} / 15 \% \mathrm{~B}$ in $1 \mathrm{~min}, 75 \% \mathrm{~A} / 25 \% \mathrm{~B}$ in $20 \mathrm{~min}, 0 \%$ $\mathrm{A} / 100 \% \mathrm{~B}$ in $15 \mathrm{~min}$, and $95 \% \mathrm{~A} / 5 \% \mathrm{~B}$ in $3 \mathrm{~min}$. The main $o$-diphenols were identified on the basis of the retention times of authentic standard references: (+)-catechin, (-)-epicatechin, chlorogenic acid, quercetin, and quercetin glysosides.

Cell culture. Human breast carcinoma cell line (MCF-7) was obtained from the American Type Culture Collection (ATCC, Manassas, VA, USA) and cultured in RPMI-1640 supplemented with $10 \%$ heat-inactivated FBS, $100 \mathrm{U} / \mathrm{ml}$ penicillin, $100 \mu \mathrm{g} / \mathrm{ml}$ streptomycin, and $1 \%$ L-glutamine. The cells were grown in a humidified atmosphere of $95 \%$ air $/ 5 \% \mathrm{CO}_{2}$ at $37^{\circ} \mathrm{C}$.

Cell viability. MCF-7 cells were seeded in 96-well plates at the density of $3 \times 10^{3}$ cells/well in RPMI complete medium. After $24 \mathrm{~h}$ incubation, cells were treated with 100, 250, and $500 \mu \mathrm{M}$ APE EqC for 24 and $48 \mathrm{~h}$. Cell viability was assessed by adding MTT solution in PBS to a final concentration of $0.5 \mathrm{mg} / \mathrm{ml}$. Cells were then incubated at $37^{\circ} \mathrm{C}$ for $4 \mathrm{~h}$ and the MTT-formazan crystals were solubilized in a solution of $4 \% 1 \mathrm{~N}$ isopropanol/hydrochloric acid on a shaking table for $20 \mathrm{~min}$. The absorbance values of the solution in each well were measured at $595 \mathrm{~nm}$ using a Bio-Rad iMark microplate reader (Bio-Rad Laboratories, Milan, Italy). Cell viability was expressed as a percentage of absorbance values in treated samples respect to that of control (100\%). All MTT experiments were performed in quadruplicate.

Thiobarbituric acid-reactive species. Thiobarbituric acidreactive species (TBARS) were determined on aliquots $(250 \mu \mathrm{l})$ of cell culture medium of not treated cells (control) or after $48 \mathrm{~h}$ treatment with 100, 250 and $500 \mu \mathrm{M}$ EqC APE. TBARS were measured as previously described (25). Briefly, samples were incubated with a solution consisting of $0.5 \mathrm{ml}$ of $20 \%$ acetic acid, and $0.5 \mathrm{ml}$ of $0.78 \%$ aqueous solution of thiobarbituric acid ( $\mathrm{pH} \mathrm{3.5)}$, heated at $95^{\circ} \mathrm{C}$ for $45 \mathrm{~min}$, and then centrifuged at $4000 \mathrm{rpm}$ for $5 \mathrm{~min}$. TBARS content was quantified at $532 \mathrm{~nm}$ with reference to malondialdehyde (extinction coefficient at $532 \mathrm{~nm}, 1.56 \times 10^{5} \mathrm{M}^{-1} \mathrm{~cm}^{-1}$ ). Result is the average of triplicate measurements of each individual experiment performed in duplicate.

Evaluation of morphological changes by phase-contrast microscopy. MCF-7 cells were cultured in 6-well tissue culture plates (Becton-Dickinson, Franklin Lanes, NJ, USA) at a seeding density of $9.0 \times 10^{4}$ cells. After overnight attachment, the cells were treated with different concentrations (100, 250 , and $500 \mu \mathrm{M} \mathrm{EqC)}$ of APE and the untreated cells were used as control. The cells were cultured for up to $48 \mathrm{~h}$ under standard culture conditions and their morphological changes were imaged using a phase-contrast microscope (Axiovert-10 Zeiss microscope).

Western blot analysis. MFC-7 cells were cultured in $10-\mathrm{cm}$ culture dishes at a seeding density of $5.5 \times 10^{5}$ cells. After overnight attachment, the cells were treated for $48 \mathrm{~h}$ with 100, 250, and $500 \mu \mathrm{M} \mathrm{EqC} \mathrm{APE}$ and the untreated cells used as control.
After the treatment, the cells were collected by centrifugation, washed twice with ice-cold PBS, and the pellets were lysed using $100 \mu \mathrm{l}$ of RIPA buffer. After incubation on ice for $30 \mathrm{~min}$, the samples were centrifuged at 18,000 $\mathrm{x} g$ in an Eppendorf microcentrifuge for $10 \mathrm{~min}$ a $4^{\circ} \mathrm{C}$, and the supernatants were quantified for protein content. Aliquots containing approximately $30 \mu \mathrm{g}$ of protein were subjected to sodium dodecyl sulfate-polyacrylamide gel electrophoresis (SDS-PAGE) and electrotransferred to nitrocellulose membranes by Trans blot turbo (Bio-Rad Laboratories). The blots were blocked with $5 \%$ non-fat dry milk in $20 \mathrm{mM}$ Tris/ $\mathrm{HCl}, \mathrm{pH} 7.5,150 \mathrm{mM}$ $\mathrm{NaCl}$ plus $0.5 \%$ Tween-20 (TBS-T). The membranes were subsequently incubated at $4{ }^{\circ} \mathrm{C}$ overnight in the $5 \%$ non-fat dry milk-TBS-T buffer, containing, for each experiment, one of the specific primary antibodies. After three times washing with TBS-T, the blots were incubated for $1 \mathrm{~h}$ at room temperature with the HRP-conjugated secondary antibodies. After four times washing, the blots were developed using enhanced chemiluminescence detection reagents ECL (Millipore Corp., Billerica, MA, USA) and exposed to X-ray film. The film was scanned by using ImageJ software (National Institutes of Health, Bethesda, MD, USA).

Flow cytometry analysis of the cell cycle. Cell cycle distribution was studied by PI staining and flow cytometry analysis using a FACScalibur (Becton-Dickinson, San Jose, CA, USA) interfaced with a Hewlett-Packard computer (model 310) for data analysis. Briefly, MCF-7 cells were plated in 6-multiwell plates at the density of $9.0 \times 10^{4}$ cells/well. After $24 \mathrm{~h}$, the medium was changed and APE was added at concentrations

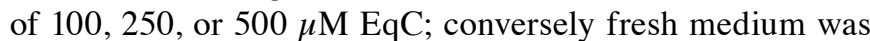
added to the control well. After $48 \mathrm{~h}$ treatment, the cells were recovered by incubation with trypsin-EDTA, washed in PBS, collected by centrifugation, fixed by resuspension in $70 \%$ ice-cold methanol/PBS and incubated overnight at $4^{\circ} \mathrm{C}$. After fixing, samples were centrifuged at $400 \mathrm{x}$ g for $5 \mathrm{~min}$, washed twice with ice-cold PBS, resuspended in $0.5 \mathrm{ml}$ DNA staining solution $(50 \mu \mathrm{g} / \mathrm{ml}$ PI and $25 \mu \mathrm{g} / \mathrm{ml}$ RNaseA in PBS), and incubated at room temperature for $1 \mathrm{~h}$ in the dark. Samples were then transferred to 5-ml Falcon tubes and stored until assayed. PI fluorescence was collected as FL2-A (linear scale) by the ModiFIT Cell Cycle Analysis software (BectonDickinson). For each sample, at least 20,000 events for each point were analyzed in at least three different experiments giving an $\mathrm{SD}$ of $<5 \%$.

Flow cytometry analysis of apoptosis. Annexin V-FITC binds phosphatidylserine residues which are translocated from the inner to the outer leaflet of the plasma membrane during the early stages of apoptosis. A flow-based Annexin V-FITC/PI double staining was used to distinguish apoptotic (Annexin V-FITCpositive, PI-positive) from necrotic (Annexin V-FITC-negative, PI-positive) cells (26). MCF-7 cells were plated in 6-multiwell plates at the density of $9.0 \times 10^{4}$ cells/well. After $24 \mathrm{~h}$, the medium was changed and APE was added at concentrations of 100,250 , or $500 \mu \mathrm{M} \mathrm{EqC}$ while fresh medium was added to the control well. After $48 \mathrm{~h}$ of treatment, the cells were detached by incubation with trypsin-EDTA, washed in PBS, collected by centrifugation, resuspended in binding buffer (10 mM HEPES, pH 7.4, $140 \mathrm{mM} \mathrm{NaCl}, 2.5 \mathrm{mM} \mathrm{CaCl}_{2}$ ), and 


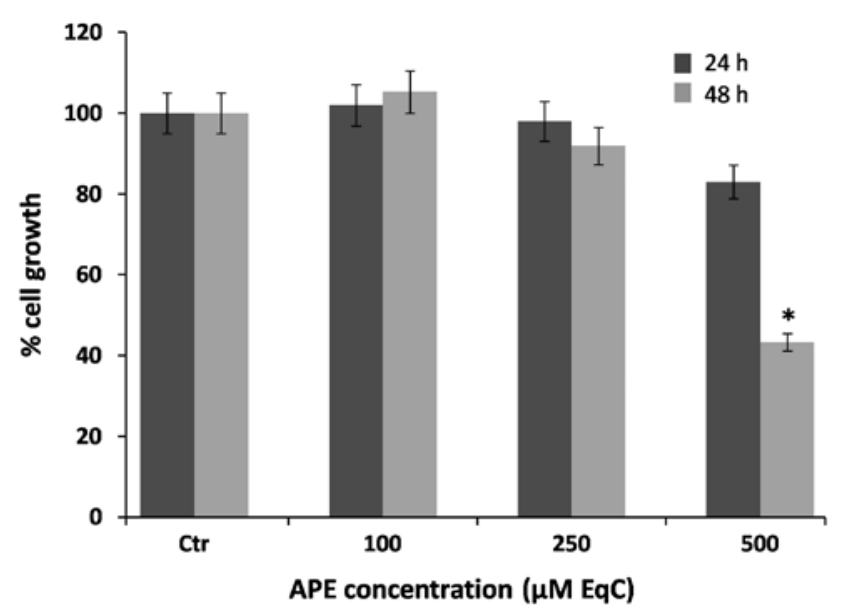

Figure 1. Effects of APE on MCF-7 cell proliferation. MCF-7 cells were cultured for 24 and $48 \mathrm{~h}$ in medium supplemented or not (Ctr) with APE 100, 250 and $500 \mu \mathrm{M} \mathrm{EqC}$. Cell viability was then assessed by MTT assay and expressed as a percentage of untreated cells. Values represent the mean $\pm \mathrm{SD}$ of three independent experiments ( $\mathrm{P}<0.05)$.

then stained with $5 \mu \mathrm{l}$ of Annexin V-FITC and $10 \mu \mathrm{l} \mathrm{PI}(20 \mu \mathrm{g} /$ $\mathrm{ml}$ ) for $30 \mathrm{~min}$ in the dark, according to the manufacturer's instructions. Analyses were performed with flow cytometry apparatus (Becton-Dickinson). Apoptosis was detected in red and green fluorescence channels with excitation wavelength of $488 \mathrm{~nm}$. For each sample, $2 \times 10^{4}$ events were acquired. Analysis was carried out by triplicate determination on at least three separate experiments.

Statistical analysis. All experiments were performed three times with replicate sample. Data are expressed as mean \pm standard deviation (SD). Comparisons between treated samples and control were performed using analysis of variance (ANOVA) plus Bonferroni's t-test. A P-value $<0.05$ was considered to indicate a statistically significant result.

\section{Results}

Total polyphenolic content of APE. The total polyphenolic content of the Annurca apple extract measured by Folin-Ciocalteu phenol reagent resulted in $125.2 \pm 7.1 \mathrm{mg}$ of catechin per $100 \mathrm{~g}$ of sample and is similar to that evaluated in other studies $(24,25)$. The HPLC analysis of APE identified (+)-catechin, (-)-epicathechin, chlorogenic acid, quercetin, and quercetin glycosides as the main Annurca apple o-diphenols (data not shown). This profile confirms the results already described in the literature $(16,24)$.

APE inhibits cell proliferation and induces lipid peroxidation. To evaluate the effect of APE on cell growth, MCF-7 cells were incubated for 24 and $48 \mathrm{~h}$ with increasing concentrations of the extract ranging from 100 to $500 \mu \mathrm{M} \mathrm{EqC}$ corresponding to $29-145 \mu \mathrm{g} \mathrm{EqC} / \mathrm{ml}$, and cell proliferation was then assessed by MTT assay. The cells appeared to be quite resistant to APE treatment. The results obtained evidenced that up to $100 \mu \mathrm{M} \mathrm{EqC} \mathrm{no} \mathrm{appreciable} \mathrm{changes} \mathrm{in}$ cell viability were observed at any time of incubation. On the other hand, at higher doses, the treatment with APE significantly reduced cell proliferation in a dose- and time-dependent

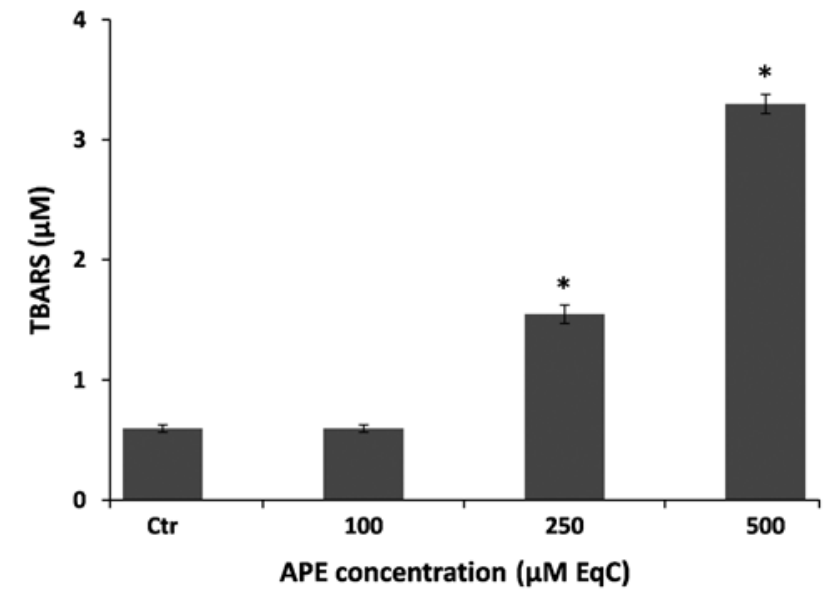

Figure 2. Effects of APE on TBARS content in MCF-7 cells. MCF-7 cells were incubated for $48 \mathrm{~h}$ in RPMI medium containing increasing amounts of APE (100, 250 and $500 \mu \mathrm{M} \mathrm{EqC)}$. TBARS content was measured at $532 \mathrm{~nm}$ as described in Materials and methods by using as reference malondialdehyde (extinction coefficient at $532 \mathrm{~nm}, 1.56 \times 10^{5} \mathrm{M}^{-1} \mathrm{~cm}^{-1}$ ). Values represent the mean $\pm \mathrm{SD}$ of three independent experiments $\left({ }^{*} \mathrm{P}<0.05\right)$.
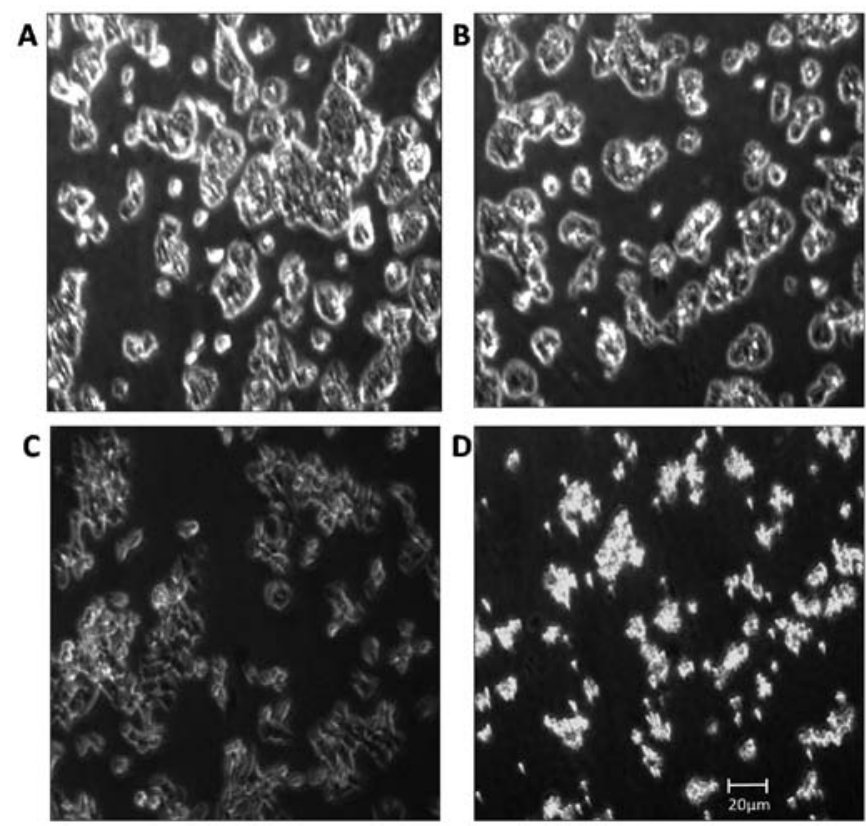

Figure 3. APE-induced morphological changes in MCF-7 cells examined by phase-contrast microscopy. Not treated MCF-7 cells (A) and MCF-7 cells treated with APE $100 \mu \mathrm{M} \mathrm{EqC} \mathrm{(B),} 250 \mu \mathrm{M} \mathrm{EqC} \mathrm{(C),} 500 \mu \mathrm{M} \mathrm{EqC} \mathrm{(D).}$ Original magnification, $\mathrm{x} 100$. Bar, $20 \mu \mathrm{m}$.

manner (Fig. 1). It has to be noted that after $24 \mathrm{~h}$ incubation, $250 \mu \mathrm{M} \mathrm{EqC}$ and $500 \mu \mathrm{M} \mathrm{EqC} \mathrm{APE} \mathrm{exerted} \mathrm{only} \mathrm{a} \mathrm{poor} \mathrm{cell}$ growth inhibitory effect reducing cell proliferation to approximately 98 and 83\%, respectively, compared to control cells. In contrast, a prolonged incubation of $48 \mathrm{~h}$ resulted in a severe loss of cell viability that decreases to $43.5 \%$, a value near the $\mathrm{IC}_{50}$, in the presence of APE $500 \mu \mathrm{M} \mathrm{EqC}$. Parallel direct cell counting provided similar results (data not shown). Based on these findings, we selected for further investigations an incubation time of $48 \mathrm{~h}$.

Free radicals are involved in cell death induction in a number of systems and membrane phospholipids represent 

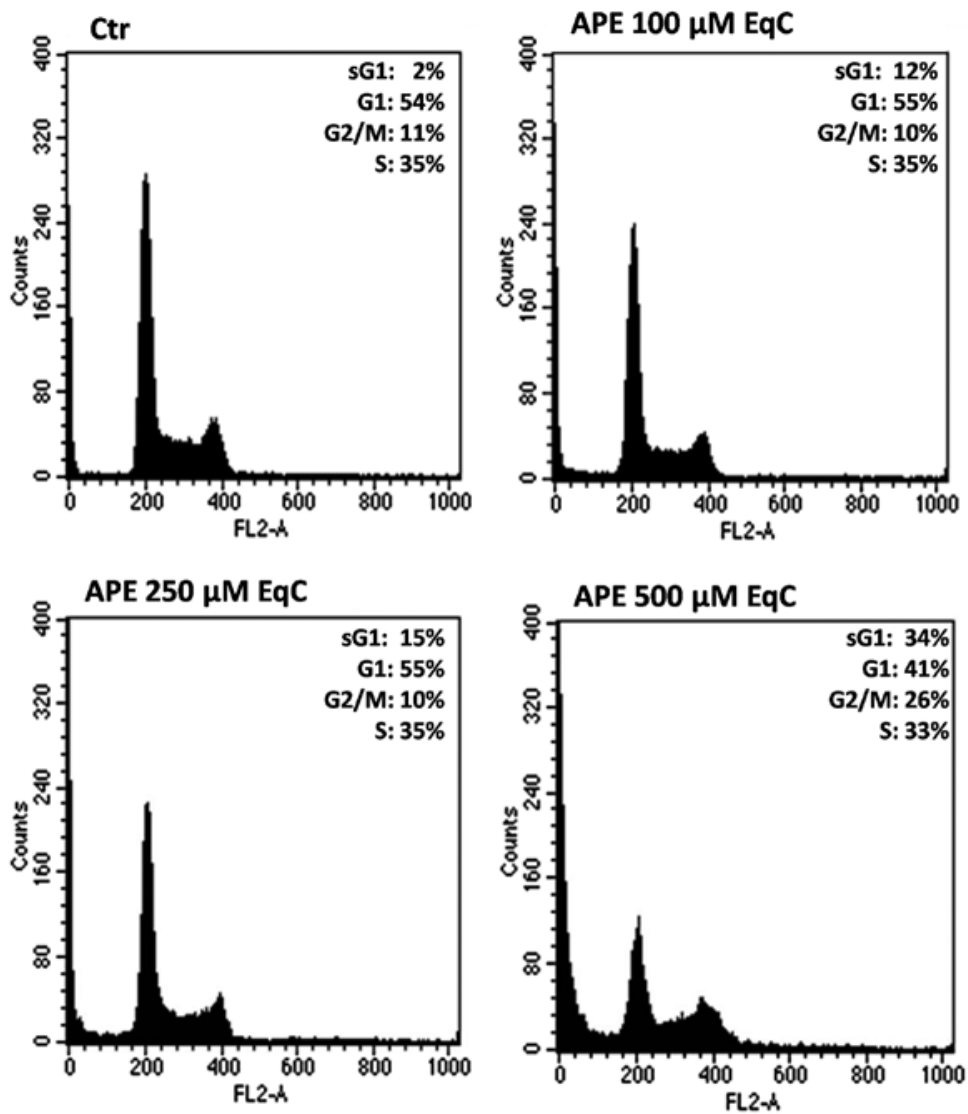

Figure 4. Effects of APE on cell cycle in MCF-7 cells. Cells were cultured for $48 \mathrm{~h}$ in medium supplemented or not (Ctr) with APE 100, 250 and $500 \mu \mathrm{M} \mathrm{EqC}$. FACS analysis was then performed. Representative FACS histograms of PI-stained MCF-7 cells are shown. The percentage of hypodiploid sub-G1 and of each cell cycle phase is indicated. Data represent the average of three independent experiments.

one of the major target of oxidative stress in cells. It has been shown that lipid hydroperoxides as well as lipid peroxidation initiators, such as ROS, are involved in signaling pathways that control cell proliferation, differentiation, maturation, and apoptosis $(1,27)$. Moreover, it has been proposed that lipid peroxidation may represent a protective mechanism in breast cancer (27).

In order to investigate whether an oxidative stress could be produced under our experimental conditions, we evaluated lipid peroxidation by measuring the extent of lipid degradation products such as, malondyaldehyde and other aldehydes reactive to thiobarbituric acid after $48 \mathrm{~h}$ incubation of MCF-7 cells in the presence of increasing amounts of APE. It is interesting to note that, in analogy with the effect exerted on cell viability, APE is able to cause lipid peroxidation only at concentration $>100 \mu \mathrm{M} \mathrm{EqC}$ inducing, at $250 \mu \mathrm{M} \mathrm{EqC}$ and $500 \mu \mathrm{M} \mathrm{EqC}$ concentration, respectively, an increase of TBARS cell content of 3- and 6-fold higher than the untreated cells (Fig. 2). These results indicate that, at elevated concentrations, apple polyphenols may act as pro-oxidants and may induce growth inhibition probably enhancing intracellular ROS oxidative stress.

APE induces morphological changes in MCF-7 cells. MCF-7cells were incubated for $48 \mathrm{~h}$ with 100,250 , and $500 \mu \mathrm{M} \mathrm{EqC}$ APE, and the morphology of treated cells was then analyzed with a phase-contrast microscope and compared with the untreated cells (Fig. 3). The results obtained indicated that the cells treated with APE $100 \mu \mathrm{M} \mathrm{EqC} \mathrm{(Fig.} \mathrm{3B)} \mathrm{maintained} \mathrm{the}$ characteristic epithelial morphology and prolific growth as a monolayer, quite similar to untreated MCF-7 cells (Fig. 3A). On the contrary, the cells treated with APE $250 \mu \mathrm{M} \mathrm{EqC} \mathrm{(Fig.} \mathrm{3C)}$ and $500 \mu \mathrm{M} \mathrm{EqC} \mathrm{(Fig.} \mathrm{3D)} \mathrm{displayed} \mathrm{morphological} \mathrm{altera-}$ tions such as, shrinkage and cytoplasmic condensation, cell rounding, poor adherence, and cell detachment. Altogether the evidence suggests that APE is able to commit MCF-7 cells to a type of death that mimics apoptosis.

APE induces cell cycle arrest at G2/M by downregulation of cyclin D1 and upregulation of p21 and p53. Recent literature data have highlighted the chemopreventive and anticancer properties of polyphenolic compounds and polyphenol-rich nutritional sources. Moreover, several recent investigations have elucidated the mechanisms by which polyphenols are able to modulate some cellular events such as, cell cycle arrest by decreasing cyclin levels, and apoptosis induction (28).

To verify whether APE caused cell cycle perturbation in MCF-7 cells, we evaluated the cell distribution in the cell cycle phases by flow cytometric analysis. In addition, the severe morphological changes observed in APE-treated MCF7-cells under the inverted phase-contrast microscope prompted us to further examine whether the APE-induced cell death was a consequence of activation of apoptosis. Therefore, we also looked at the proportion of cells with hypodiploid DNA content (sub-G1 population), characteristic of cells having undergone DNA fragmentation, a biochemical hallmark of apoptosis. 
$\mathbf{A}$

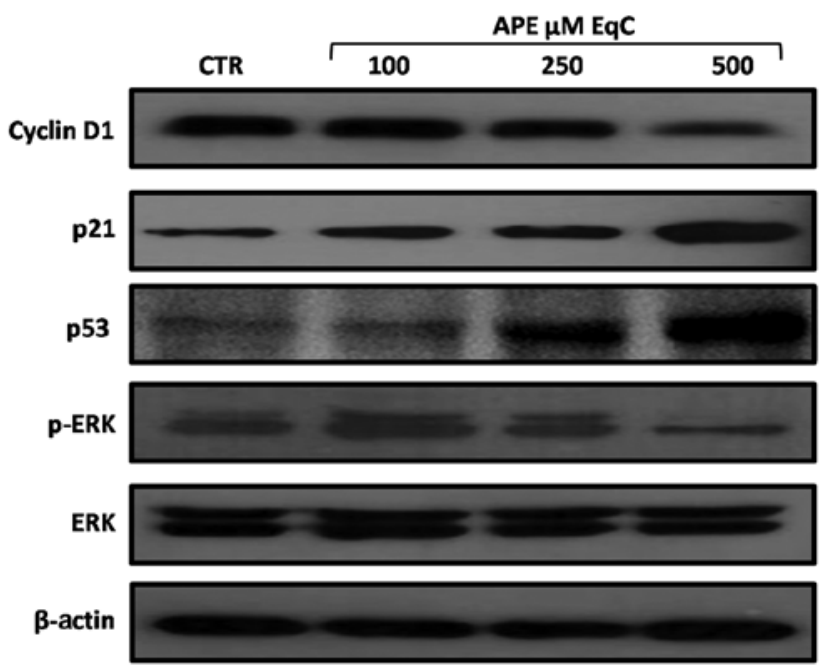

B
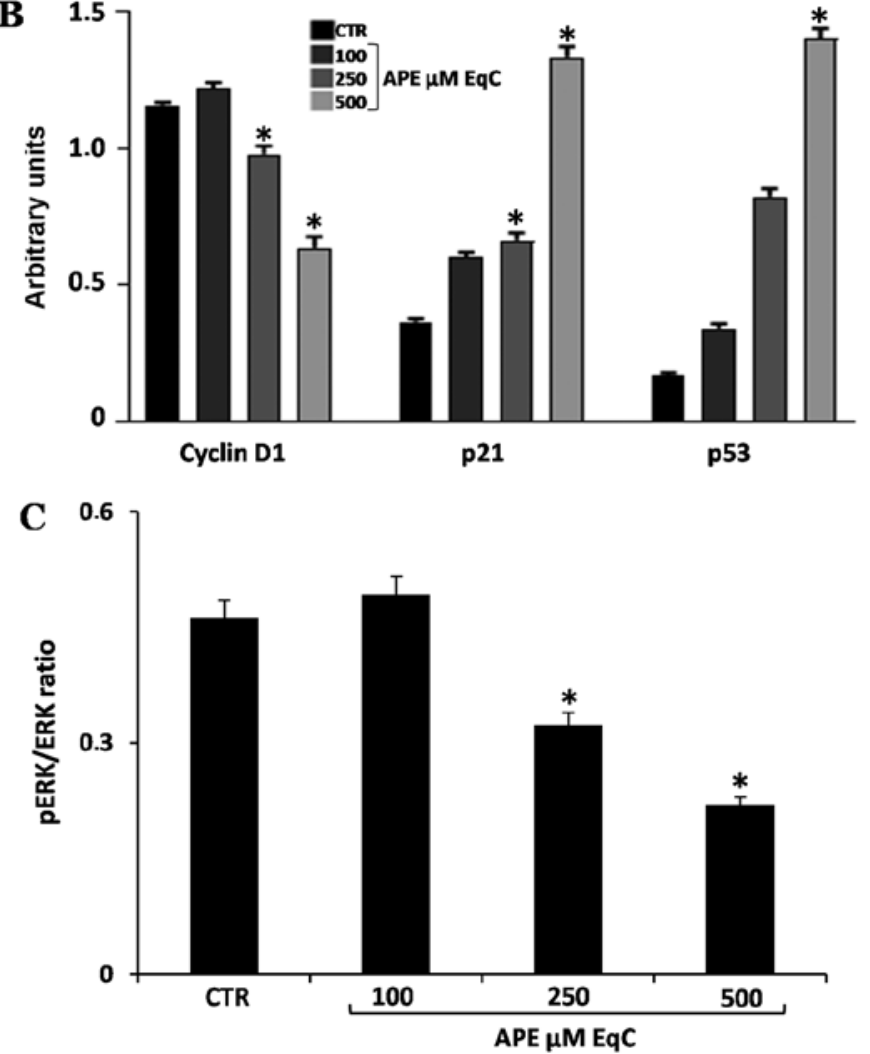

Figure 5. Effects of APE on the levels of some relevant cell cycle- and proliferation-regulating proteins in MCF-7 cells. Cells were cultured in medium supplemented or not (Ctr) with APE 100, 250 and $500 \mu \mathrm{M} \mathrm{EqC}$ for $48 \mathrm{~h}$. Then, $30 \mu \mathrm{g}$ of cell extracts were subjected to SDS-PAGE and blotted with antibodies against the indicated proteins. $\beta$-actin was used as a standard for the equal loading of protein in the lanes. (A) Western blot assay for the expression of cyclin D1, p21, p53, ERK1/2 and p-ERK1/2. (B) Densitometric quantification of cyclin D1, p21, and p53. (C) The graphs show the densitometric intensity of pERK/ERK band ratio in different conditions. The intensity of signals was expressed as arbitrary units. ${ }^{*} \mathrm{P}<0.05$ versus control untreated cells. Data represent the average of three independent experiments.

MCF-7 cells were exposed to increasing concentrations of $\operatorname{APE}(100,250$, and $500 \mu \mathrm{M} \mathrm{EqC})$, harvested at $48 \mathrm{~h}$, and examined for DNA content after proper staining with PI. Fig. 4 shows that the treatment of cells with 100 and $250 \mu \mathrm{M} \mathrm{EqC}$ APE does not cause any evident effect on cell proliferation while $500 \mu \mathrm{M} \mathrm{EqC} \mathrm{APE} \mathrm{induces} \mathrm{a} \mathrm{cell} \mathrm{cycle} \mathrm{arrest} \mathrm{at} \mathrm{G} 2 / \mathrm{M}$, as evidenced by the significant increase of cell percentage in this phase of the cell cycle (26\%) respect to untreated cells (11\%). Moreover, a dose-dependent increase of sub-G1 population can be observed that becomes clearly evident at $500 \mu \mathrm{M} \mathrm{EqC}$ APE (34\%) suggesting that the cytotoxic activity of APE in MCF7-cells occurs via apoptosis.

To gain further insight into the molecular mechanism of cell cycle arrest induced by APE, we analyzed the expression level of some relevant cell proliferation- and cell cycle-regulators such as, cyclin D1, cyclin-dependent kinase inhibitor 1 (p21) and 553 transcription factor. Thus, MCF-7 cells were exposed to 100,250 , and $500 \mu \mathrm{M} \mathrm{EqC} \mathrm{APE} \mathrm{for} 48 \mathrm{~h}$, after which cell extracts were analyzed by western blotting. As shown in Fig. 5, the treatment for $48 \mathrm{~h}$ with APE induced a significant dose-dependent increase in the level of p53 and p21 proteins. It has to be pointed out that the tumor suppressor p53 is a transcription factor that regulates a broad range of processes among which cell cycle arrest, senescence, and apoptosis are the best characterized. In vitro and in vivo studies have shown that polyphenols such as, epigallocatechin, resveratrol, and curcumin as well as nutritional sources of polyphenols are able to upregulate p53 protein in several cancer cell lines (28-32) and that the polyphenol-induced stabilization and expression of p53 is often associated with a $\mathrm{G} 1$ or G2/M phase cell cycle arrest (33). It has also been reported that tumor suppressors, like p53 and its analogs, are key molecular targets of polyphenols responsible for their pro-apoptotic effect in human and animal cancer models through the transcriptional regulation of target genes such as p21, Bax, and PUMA (32).

From the western blot analysis reported in Fig. 5 we can observe that concomitantly with the increase of p53 and p21, the level of cyclin D1 was decreased in a dose-dependent manner. In agreement with our results it has been recently reported that epigallocatechin-3-gallate, the major polyphenolic component of green tea, induces apoptosis and cell cycle arrest in colorectal cancer cells by downregulating cyclin D1 and upregulating p21 (34).

Cyclin D1 is a key factor regulating cell proliferation, this cyclin links the extracellular signals to cell cycle advancement (35). Cyclin D1 levels must be elevated during G1 phase to start DNA synthesis, but then they must be suppressed during S phase to allow DNA synthesis. If the cell has to continue to proliferate, cyclin D1 levels must be induced once again during G2 phase. This induction depends upon the activity of proliferative signaling molecules, and ensures that the extracellular environment continues to be conducive for growth (36). 

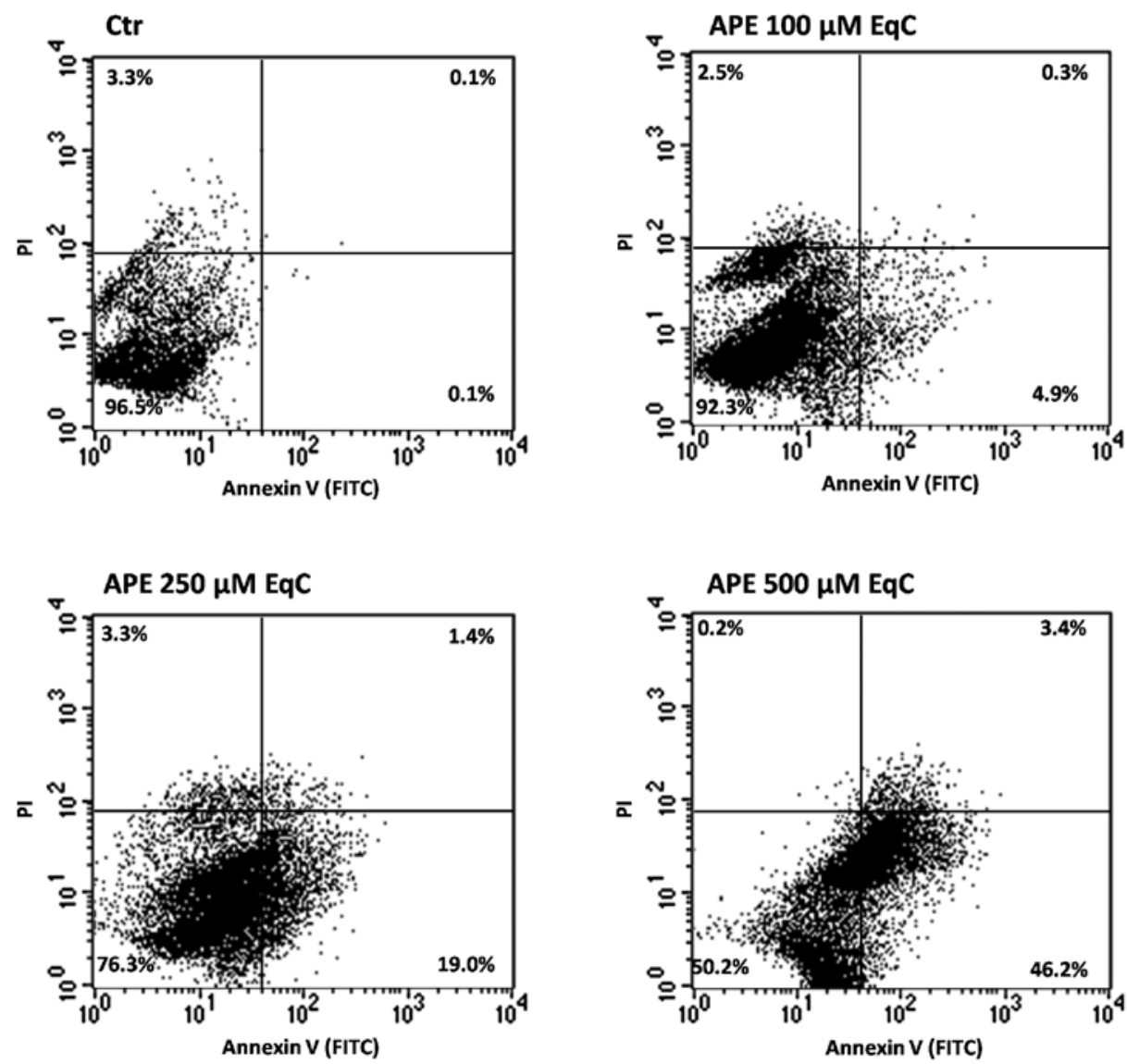

Figure 6. Evaluation of apoptosis induced by APE in MCF-7 cells. Cells were cultured for $48 \mathrm{~h}$ in medium supplemented or not (Ctr) with APE 100,250 and $500 \mu \mathrm{M} \mathrm{EqC}$. FACS analysis was then performed. Representative dot plots V-FITC (x-axis)/PI (y-axis) of both Annexin V-FITC and PI-stained MCF-7 cells The percentage of cells is reported in the quadrants. Viable cells, lower left; non-viable necrotic cells, upper left; early apoptotic cells, lower right; late apoptotic cells, upper right.

For its prominence, cyclin D1 is an intriguing target in anticancer agent development. Many anticancer drugs induce cyclin D1 degradation in several tumor cell lines. Moreover, increased cyclin D1 degradation in cancer cells, is achieved also by various natural compounds such as polyphenols (37). Altogether our results indicate that cyclin D1 degradation and p53 and p21 overexpression contribute to APE-induced growth inhibition in MCF-7 cells.

APE inhibits ERK1/2 phosphorylation. MAPK cascade is a major cell signaling pathway triggered by ROS, leading to activation of numerous transcription factors which control DNA repair, cell cycle, apoptosis, or the immune system, among other processes. Major MAPKs can be grouped into four subfamilies: extracellular signal-regulated kinases (ERKs), c-Jun amino terminal kinase (JNK), p38 MAPK, and big-1 kinases (BMAPK-1). The whole pathway is regulated by various extracellular signals and, in this manner, it regulates distinct and even opposing cellular phenomena, such as proliferation, differentiation, survival and apoptosis (38). Moreover, in human hepatocellular carcinoma cell lines, multiple anticancer effects such as inhibition of cellular proliferation as well as induction of cell cycle arrest and apoptosis have been achieved by blocking ERK signaling (39).

In order to investigate whether the antiproliferative effect induced by APE in MCF-7 cells was related to ERK, we analyzed the expression and activation (phosphorylation) of ERK by western blotting. As reported in Fig. 5, APE caused a strong dose-dependent inhibition of ERK phosphorylation and a decrease of $\mathrm{pERK} / \mathrm{ERK}$ ratio while no variations in the total amount of ERK1/2 protein levels occur at any of the concentrations tested. The obtained results suggest that ERK inactivation may contribute to the G2/M cell cycle arrest and to the antiproliferative activity of APE even if the detailed molecular mechanisms underlying the APE-induced ERK signaling modulation needs to be further investigated. In agreement with our data it has been reported that red wine polyphenols inhibit the proliferation of colon carcinoma cells by modulating MAPK intracellular signal transduction pathways (40) and that quercetin may induce apoptosis in HepG2 cells by direct activation of caspase cascade and by inhibiting survival signaling (41).

APE induces apoptosis through the mitochondrial pathway. The occurrence of apoptosis in MCF-7 cells upon APE treatment was assessed by FACS analysis after double labeling of cells with Annexin V and PI. Representative pictures are shown in Fig. 6 together with the percentage of apoptotic cells. The exposure of cells for $48 \mathrm{~h}$ to Annurca apple polyphenols caused a dose-dependent increase of apoptotic cells respect to the control. A low percentage of early apoptotic cells (4.9\%) is already evident after exposure to $100 \mu \mathrm{M} \mathrm{EqC} \mathrm{APE}$. This 

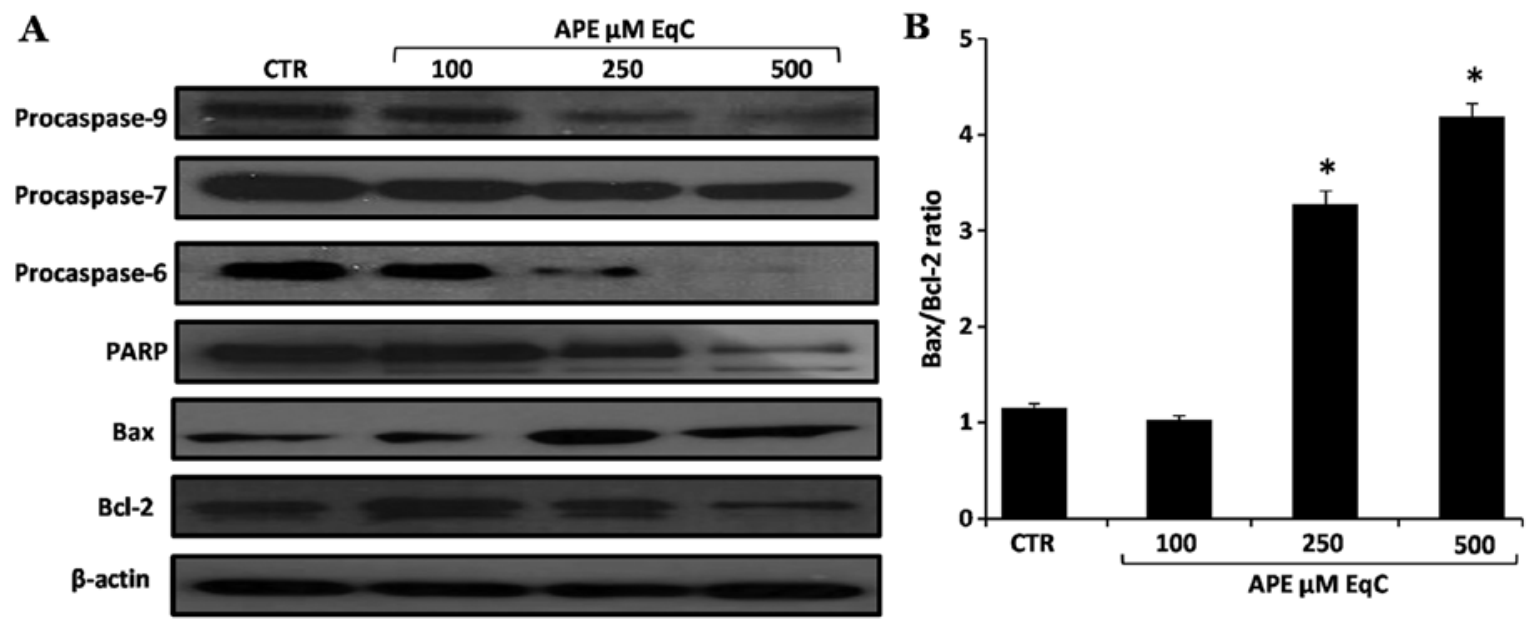

Figure 7. Effects of APE on the levels of some relevant apoptosis regulating proteins in MCF-7 cells. Cells were cultured in medium supplemented or not (Ctr) with APE 100, 250 and $500 \mu \mathrm{M} \mathrm{EqC}$. Then, $30 \mu \mathrm{g}$ of cell extracts were subjected to SDS-PAGE and blotted with antibodies against the indicated proteins; the housekeeping protein $\beta$-actin was used as loading control. (A) Western blot assay for the expression of pro-caspase-6, -7, -9, PARP, Bax, and Bcl-2. The graph shows the densitometric intensity of Bax/Bcl-2 band ratio in different conditions. The intensities of signals were expressed as arbitrary units. " $\mathrm{P}<0.05$ versus control cells. All results were obtained from at least three independent experiments.

value significantly increases in the cells treated with APE $250 \mu \mathrm{M} \mathrm{EqC} \mathrm{(19 \% )} \mathrm{and} 500 \mu \mathrm{M} \mathrm{EqC} \mathrm{(46.2 \% ).}$

The APE-induced lipid peroxidation and the highly increased expression levels of $\mathrm{p} 53$ after cell incubation with APE led us to hypothesize that the apoptotic process in MCF-7 cells occurs through a ROS-dependent mitochondrial pathway.

The balance of the expression of anti- and pro-apoptotic members of the Bcl-2 gene family is one of the major mechanisms that regulate this type of apoptotic process in mammalian cells (42). Therefore, to determine whether APE-induced apoptosis in MCF-7 cells was associated with the modulation of members of this protein family, we examined the expression of Bcl-2 and Bax proteins. The results obtained, reported in Fig. 7, show that APE treatment resulted in the increased expression of pro-apoptotic Bax while the level of the anti-apoptotic $\mathrm{Bcl}-2$ was decreased. We then tested the effect of APE on the cascade of caspases that are crucial initiators or effectors in this cell death pathway. Western blot analysis shows that the increased $\mathrm{Bax} / \mathrm{Bcl}-2$ ratio coincides with the activation of the initiator caspase- 9 and of the executioner caspase- 6 and -7 and with the increased PARP cleavage (Fig. 7). Altogether these results indicate that the activation of the mitochondrial pathway is involved in the apoptosis of MCF-7 cells induced by APE.

\section{Discussion}

The potential of dietary components, in particular polyphenols, as antiproliferative agents has been evidenced in the literature, and growing scientific interest is focused on identifying the biological mechanisms and the signal transduction pathways related to the chemopreventive activities of these compounds. Polyphenols, a heterogeneous class of phytochemicals with a wide range of pharmacological properties, appear quite intringuing molecules because of their antioxidant/pro-oxidant effects. As antioxidants, they are able to act as scavengers of ROS. Conversely, under some conditions, they can act as pro-oxidant, generating ROS and causing cellular oxidative stress (43). Such pro-oxidant effect of polyphenols seems to be responsible for apoptosis induction in cancer cells. It is speculated that the malignant cells which have an increased level of oxidative stress would be more vulnerable to further ROS attack. Thus, the conventional anticancer therapeutic strategies are based on increased ROS generation treatments which trigger apoptotic damage (44).

In the current study we show that Annurca apple polyphenol extract induces lipid peroxidation and inhibits the growth of human breast cancer MCF-7 cells by altering cell cycle kinetics and by inducing apoptosis. We also show that APE exerts its antiproliferative effect by targeting p53 and ERK1/2 signaling pathways. The following considerations deduced from the results obtained allowed us to hypothesize that the pro-apoptotic effect of Annurca apple polyphenol extract is related to its pro-oxidant activity: i) APE causes MCF-7 cells to arrest in G2/M phase of the cell cycle, and this is accompanied by a marked decrease of cyclin D1. It is well known that cyclin D1 is downregulated in presence of ROS causing a cell cycle arrest in G2/M and it has been also reported that cyclin D1 depletion is a defense mechanism to reduce ROS-induced genotoxic damages (45) and that ROS affect the proteasomal degradation of cyclin D1 (46); ii) APE induces a marked increase of p53. It is well known that in presence of oxidative stress, the tumor suppressor p53 has a dual action increasing the synthesis of pro- or anti-oxidant enzymes depending to high or low levels of ROS, respectively. In response to low levels of oxidative stress, p53 exhibits antioxidant activities and assists the survival and repair of cells with minor injuries while in response to high levels of ROS p53 exhibits pro-oxidant activities and induces mitochondrial apoptosis (47); iii) APE causes a decrease of phosphorylated ERK1/2 protein. Because the activation of ERK1/2 is necessary for cell survival and proliferation, the inhibition of ERK1/2 by APE contributes to the increased occurrence of cell death.

The ERK signaling pathway is activated in response to certain situations of cellular stress, and it is implicated in 
cellular death or survival signaling. Generally, the ERK signal transduction pathway is activated by growth factors and is important for proliferation. Nevertheless, ERK has been reported to be inactivated by p53-regulated transcription of phosphatases MKP1, PAC1 and DUSP5. It has been shown, that in response to oxidative stress, MAPKs phosphorylate and activate p53 leading to upregulation of PAC1 and DUSP5 phosphatases. The resulting inactivation of ERK1/2 in turn causes cell cycle arrest and apoptosis (48). The functional interaction between p53 and ERK 1/2 suggests the existence of a reciprocal negative regulation between these signaling pathways. ERK 1/2-dependent p53 phosphorylation induced by different stressful stimuli can lead to p53-dependent cell cycle arrest and apoptosis. On the other hand, activated p53 is able to suppress ERK1/2 signaling via the transcriptional activation of members of the dual specificity phosphatase family thus facilitating p53-induced apoptosis. On the basis of these considerations, it is possible to assume that the balance between the p53 and MAPK pathways will determine the final cell response to oxidative stress.

In conclusion, our findings suggest that APE-mediated ROS generation probably represents the central trigger for the antiproliferative activity of these compounds in MCF-7 cells and allow us to propose the Annurca apple polyphenol extract as a promising target for further investigations finalized to the design of innovative adjuvant therapies in breast cancer treatments.

\section{References}

1. Reczek CR and Chandel NS: The two faces of reactive oxygen species in cancer. Annu Rev Cancer Biol 1: 79-98, 2017.

2. Wang P, Yang HL, Yang YJ, Wang L and Lee SC: Overcome cancer cell drug resistance using natural products. Evid Based Complement Alternat Med 2015: 767136, 2015.

3. Li L and Leung PS: Use of herbal medicines and natural products: An alternative approach to overcoming the apoptotic resistance of pancreatic cancer. Int J Biochem Cell Biol 53: 224-236, 2014.

4. Hemaiswarya $S$ and Doble M: Potential synergism of natural products in the treatment of cancer. Phytother Res 20: 239-249, 2006.

5. León-González AJ, Auger C and Schini-Kerth VB: Pro-oxidant activity of polyphenols and its implication on cancer chemoprevention and chemotherapy. Biochem Pharmacol 98: 371-380, 2015.

6. Rengarajan T and Yaacob NS: The flavonoid fisetin as an anticancer agent targeting the growth signaling pathways. Eur J Pharmacol 789: 8-16, 2016.

7. Batra P and Sharma AK: Anti-cancer potential of flavonoids: Recent trends and future perspectives. 3 Biotech 3: 439-459, 2013.

8. Khan HY, Zubair H, Ullah MF, Ahmad A and Hadi SM: A prooxidant mechanism for the anticancer and chemopreventive properties of plant polyphenols. Curr Drug Targets 13: 1738-1749, 2012.

9. Crozier A, Jaganath IB and Clifford MN: Dietary phenolics: Chemistry, bioavailability and effects on health. Nat Prod Rep 26: 1001-1043, 2009.

10. Vauzour D, Rodriguez-Mateos A, Corona G, Oruna-Concha MJ and Spencer JP: Polyphenols and human health: Prevention of disease and mechanisms of action. Nutrients 2: 1106-1131, 2010.

11. Boyer J and Liu RH: Apple phytochemicals and their health benefits. Nutr J 3: 5, 2004.

12. Kern M, Tjaden Z, Ngiewih Y, Puppel N, Will F, Dietrich H, Pahlke G and Marko D: Inhibitors of the epidermal growth factor receptor in apple juice extract. Mol Nutr Food Res 49: 317-328, 2005.

13. Sun J, Chu YF, Wu X and Liu RH: Antioxidant and antiproliferative activities of common fruits. J Agric Food Chem 50: 7449-7454, 2002.
14. Tow WW, Premier R, Jing $\mathrm{H}$ and Ajlouni S: Antioxidant and antiproliferation effects of extractable and nonextractable polyphenols isolated from apple waste using different extraction methods. J Food Sci 76: T163-T172, 2011.

15. Lo Scalzo R, Testoni A and Genna A: 'Annurca' apple fruit, a southern Italy apple cultivar: Textural properties and aroma composition. Food Chem 73: 333-343, 2001.

16. Napolitano A, Cascone A, Graziani G, Ferracane R, Scalfi L, Di Vaio C, Ritieni A and Fogliano V: Influence of variety and storage on the polyphenol composition of apple flesh. J Agric Food Chem 52: 6526-6531, 2004.

17. Tenore GC, Campiglia P, Stiuso P, Ritieni A and Novellino E: Nutraceutical potential of polyphenolic fractions from Annurca apple (M. pumila Miller cv Annurca). Food Chem 140: 614-622, 2013.

18. Fini L, Piazzi G, Daoud Y, Selgrad M, Maegawa S, Garcia M, Fogliano V, Romano M, Graziani G, Vitaglione P, et al: Chemoprevention of intestinal polyps in $\mathrm{Apc}^{\mathrm{Min} /+}$ mice fed with western or balanced diets by drinking Annurca apple polyphenol extract. Cancer Prev Res (Phila) 4: 907-915, 2011.

19. Fini L, Selgrad M, Fogliano V, Graziani G, Romano M, Hotchkiss E, Daoud YA, De Vol EB, Boland CR and Ricciardiello L: Annurca apple polyphenols have potent demethylating activity and can reactivate silenced tumor suppressor genes in colorectal cancer cells. J Nutr 137: 2622-2628, 2007.

20. D'Angelo S, La Porta R, Napolitano M, Galletti P, Quagliuolo L and Boccellino M: Effect of Annurca apple polyphenols on human $\mathrm{HaCaT}$ keratinocytes proliferation. J Med Food 15: 1024-1031, 2012.

21. Wang S, Bai L, Lu J, Liu L, Yang CY and Sun H: Targeting inhibitors of apoptosis proteins (IAPs) for new breast cancer therapeutics. J Mammary Gland Biol Neoplasia 17: 217-228, 2012.

22. Dou QP: Molecular mechanisms of green tea polyphenols. Nutr Cancer 61: 827-835, 2009.

23. Singleton VL, Orthofer R and Lamuela-Raventos RM: Analysis of total phenols and other oxidation substrates and antioxidants by means of Folin-Ciocalteu reagent. Methods Enzymol 299: 152-178, 1999.

24. D'Angelo S, Cimmino A, Raimo M, Salvatore A, Zappia V and Galletti P: Effect of reddening-ripening on the antioxidant activity of polyphenol extracts from cv. 'Annurca' apple fruits. J Agric Food Chem 55: 9977-9985, 2007.

25. D'Angelo S and Sammartino D: Protective effect of Annurca apple extract against oxidative damage in human erythrocytes. Curr Nutr Food Sci 11: 248-256, 2015.

26. Vermes I, Haanen C, Steffens-Nakken H and Reutelingsperger C: A novel assay for apoptosis. Flow cytometric detection of phosphatidylserine expression on early apoptotic cells using fluorescein labelled Annexin V. J Immunol Methods 184: 39-51, 1995.

27. Gago-Dominguez M, Jiang $X$ and Castelao JE: Lipid peroxidation, oxidative stress genes and dietary factors in breast cancer protection: A hypothesis. Breast Cancer Res 9: 201-211, 2007.

28. Fantini M, Benvenuto M, Masuelli L, Frajese GV, Tresoldi I, Modesti A and Bei R: In vitro and in vivo antitumoral effects of combinations of polyphenols, or polyphenols and anticancer drugs: Perspectives on cancer treatment. Int J Mol Sci 16 : 9236-9282, 2015.

29. Min NY, Kim JH, Choi JH, Liang W, Ko YJ, Rhee S, Bang H, Ham SW, Park AJ and Lee KH: Selective death of cancer cells by preferential induction of reactive oxygen species in response to (-)-epigallocatechin-3-gallate. Biochem Biophys Res Commun 421: 91-97, 2012.

30. Casanova F, Quarti J, da Costa DC, Ramos CA, da Silva JL and Fialho E: Resveratrol chemosensitizes breast cancer cells to melphalan by cell cycle arrest. J Cell Biochem 113: 2586-2596, 2012.

31. Lee HP, Li TM, Tsao JY, Fong YC and Tang CH: Curcumin induces cell apoptosis in human chondrosarcoma through extrinsic death receptor pathway. Int Immunopharmacol 13: 163-169, 2012.

32. Etienne-Selloum N, Dandache I, Sharif T, Auger C and Schini-Kerth VB: Polyphenolic compounds targeting p53-family tumor suppressors: current progress and challenges. In: Future Aspects of Tumor Suppressor Gene. Cheng Y (ed). InTech, pp129-166, 2013. https://doi.org/10.5772/56102.

33. Taylor WR and Stark GR: Regulation of the G2/M transition by p53. Oncogene 20: 1803-1815, 2001. 
34. Zhang X, Min KW, Wimalasena J and Baek SJ: Cyclin D1 degradation and 21 induction contribute to growth inhibition of colorectal cancer cells induced by epigallocatechin-3-gallate. J Cancer Res Clin Oncol 138: 2051-2060, 2012.

35. Sherr CJ: D-type cyclins. Trends Biochem Sci 20: 187-190, 1995.

36. Yang K, Hitomi M and Stacey DW: Variations in cyclin D1 levels through the cell cycle determine the proliferative fate of a cell. Cell Div 1: 32, 2006.

37. Alao JP: The regulation of cyclin D1 degradation: Roles in cancer development and the potential for therapeutic invention. Mol Cancer 6: 24, 2007.

38. Cagnol S and Chambard JC: ERK and cell death: Mechanisms of ERK-induced cell death - apoptosis, autophagy and senescence. FEBS J 277: 2-21, 2010

39. Chaparro M, González Moreno L, Trapero-Marugán M Medina J and Moreno-Otero R: Review article: Pharmacological therapy for hepatocellular carcinoma with sorafenib and other oral agents. Aliment Pharmacol Ther 28: 1269-1277, 2008.

40. Briviba K, Pan L and Rechkemmer G: Red wine polyphenols inhibit the growth of colon carcinoma cells and modulate the activation pattern of mitogen-activated protein kinases. J Nutr 132: 2814-2818, 2002.

41. Granado-Serrano AB, Martín MA, Bravo L, Goya L and Ramos S: Quercetin induces apoptosis via caspase activation, regulation of $\mathrm{Bcl}-2$, and inhibition of PI-3-kinase/Akt and ERK pathways in a human hepatoma cell line (HepG2). J Nutr 136: 2715-2721, 2006.
42. Hardwick JM and Soane L: Multiple functions of BCL-2 family proteins. Cold Spring Harb Perspect Biol 5: pii: a008722, 2013.

43. Babich H, Schuck AG, Weisburg JH and Zuckerbraun HL: Research strategies in the study of the pro-oxidant nature of polyphenol nutraceuticals. J Toxicol 2011: 467305, 2011.

44. Trachootham D, Lu W, Ogasawara MA, Nilsa RD and Huang P: Redox regulation of cell survival. Antioxid Redox Signal 10: 1343-1374, 2008

45. Burch PM and Heintz NH: Redox regulation of cell-cycle re-entry: Cyclin D1 as a primary target for the mitogenic effects of reactive oxygen and nitrogen species. Antioxid Redox Signal 7: 741-751, 2005.

46. Fasanaro P, Magenta A, Zaccagnini G, Cicchillitti L, Fucile S, Eusebi F, Biglioli P, Capogrossi MC and Martelli F: Cyclin D1 degradation enhances endothelial cell survival upon oxidative stress. FASEB J 20: 1242-1244, 2006.

47. Budanov AV: The role of tumor suppressor p53 in the antioxidant defense and metabolism. Subcell Biochem 85: 337-358, 2014

48. Wu GS: The functional interactions between the p53 and MAPK signaling pathways. Cancer Biol Ther 3: 156-161, 2004. 